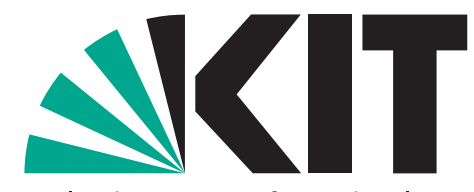

Karlsruher Institut für Technologie

\title{
A profit model for spread trading with an application to energy futures
}

by Takashi Kanamura, Svetlozar T. Rachev, Frank J. Fabozzi

No. 27 | MAY 2011

\section{WORKING PAPER SERIES IN ECONOMICS}

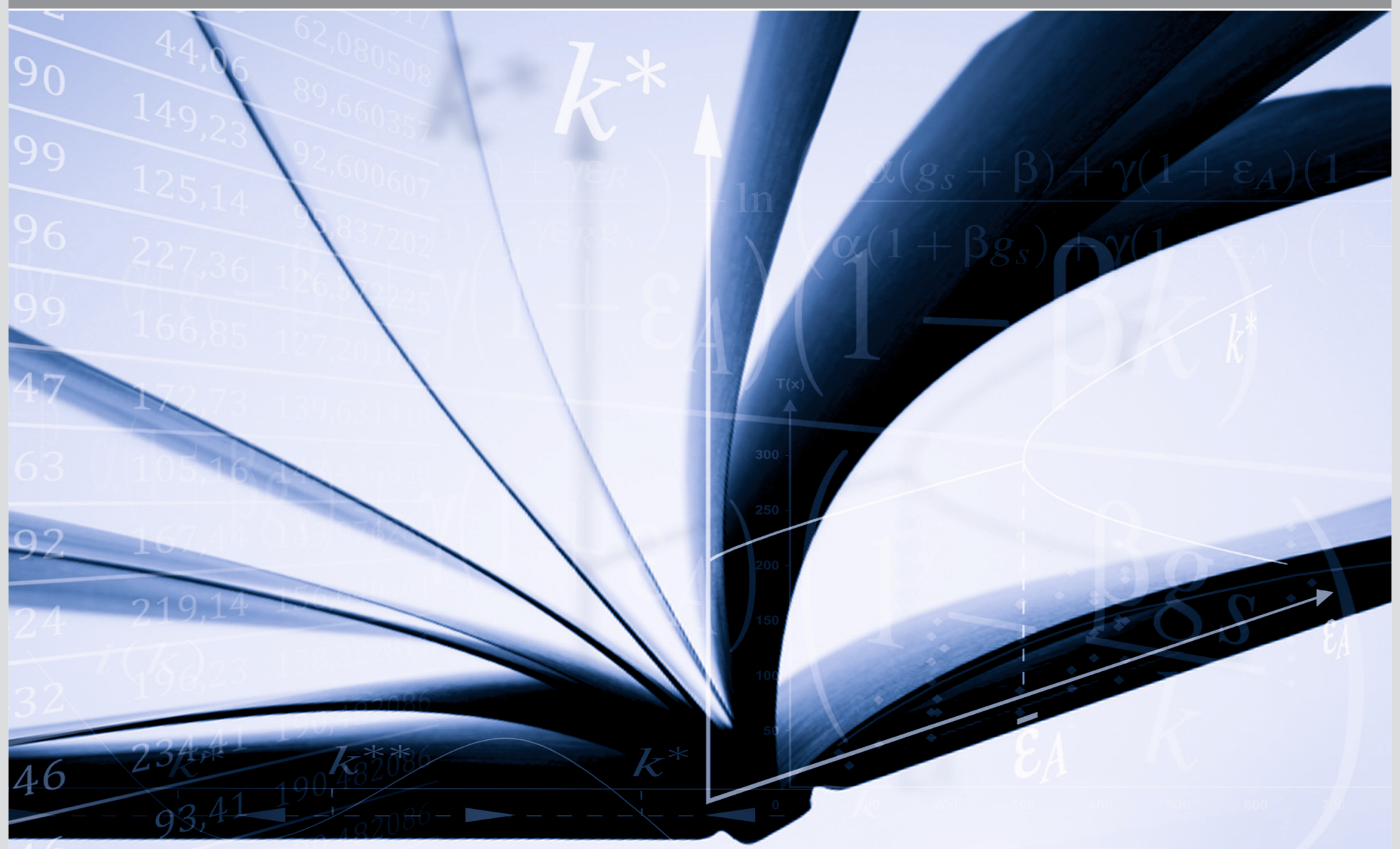




\section{Impressum}

Karlsruher Institut für Technologie (KIT)

Fakultät für Wirtschaftswissenschaften

Institut für Wirtschaftspolitik und Wirtschaftsforschung (IWW)

Institut für Wirtschaftstheorie und Statistik (ETS)

Schlossbezirk 12

76131 Karlsruhe

KIT - Universität des Landes Baden-Württemberg und nationales Forschungszentrum in der Helmholtz-Gemeinschaft

Working Paper Series in Economics

No. 27, May 2011

ISSN 2190-9806

econpapers.wiwi.kit.edu 


\title{
A Profit Model for Spread Trading with an Application to Energy Futures
}

\author{
Takashi Kanamura \\ J-POWER \\ Svetlozar T. Rachev* \\ Chair of Econometrics, Statistics and Mathematical Finance, School of Economics and Business \\ Engineering University of Karlsruhe and KIT, Department of Statistics and Applied Probability \\ University of California, Santa Barbara and Chief-Scientist, FinAnalytica INC
}

Frank J. Fabozzi

Yale School of Management

October 19, 2009

\begin{abstract}
This paper proposes a profit model for spread trading by focusing on the stochastic movement of the price spread and its first hitting time probability density. The model is general in that it can be used for any financial instrument. The advantage of the model is that the profit from the trades can be easily calculated if the first hitting time probability density of the stochastic process is given. We then modify the profit model for a particular market, the energy futures market. It is shown that energy futures spreads are modeled by using a meanreverting process. Since the first hitting time probability density of a mean-reverting process is approximately known, the profit model for energy futures price spreads is given in a computable way by using the parameters of the process. Finally, we provide empirical evidence for spread trades of energy futures by employing historical prices of energy futures (WTI crude oil, heating oil, and natural gas futures) traded on the New York Mercantile Exchange. The results suggest that natural gas futures trading may be more profitable than WTI crude oil and heating oil due to its high volatility in addition to its long-term mean reversion, which offers supportive evidence of the model prediction.
\end{abstract}

Key words: Futures spread trading, energy futures markets, mean-reverting process, first hitting time probability density, profit model, WTI crude oil, heating oil, natural gas

JEL Classification: C51, G29, Q40

\footnotetext{
${ }^{*}$ Corresponding Author: Prof. Svetlozar (Zari) T. Rachev, Chair of Econometrics, Statistics and Mathematical Finance, School of Economics and Business Engineering University of Karlsruhe and KIT, Postfach 6980, 76128 Karlsruhe, Germany, Department of Statistics and Applied Probability University of California, Santa Barbara, CA 931063110, USA and Chief-Scientist, FinAnalytica INC. E-mail: rachev@statistik.uni-karlsruhe.de. Svetlozar Rachev gratefully acknowledges research support by grants from Division of Mathematical, Life and Physical Sciences, College of Letters and Science, University of California, Santa Barbara, the Deutschen Forschungsgemeinschaft, and the Deutscher Akademischer Austausch Dienst. Views expressed in this paper are those of the authors and do not necessarily reflect those of J-POWER. All remaining errors are ours. The authors thank Toshiki Honda, Matteo Manera, Ryozo Miura, Izumi Nagayama, Nobuhiro Nakamura, Kazuhiko Ohashi, Toshiki Yotsuzuka, and seminar participants at University of Karlsruhe for their helpful comments.
} 


\section{Introduction}

A well-known trading strategy employed by hedge funds is "pairs trading." This trading strategy is categorized as a statistical arbitrage and convergence trading strategy which has typically been applied in equity markets and referred to as "spread trades." In pairs trading, the trader identifies a pair of stocks whose prices are highly correlated in the past and then starts the trades by opening the long and short positions for the selected pair. Gatev, Goetzmann, and Rouwenhorst (2006) conduct empirical tests of pairs trading applied to common stock and show that a pairs trading strategy is profitable even after taking into account transaction costs. Jurek and Yang (2007) compare the performance of their optimal mean-reversion strategy with the performance of Gatev, Goetzmann, and Rouwenhorst using simulated data and report that their strategy provides even better performance.

Although a spread trading strategy such as pairs trading has been applied primarily as a stock market trading strategy, there is no need to limit the strategy to that financial instrument because such a strategy simply requires two highly correlated prices. In fact, various specialized trades in energy futures price spreads like crack spreads are conducted in practice, where there is a welldefined relationship between petroleum and its derivative products. Spread trading in energy markets has been investigated in several studies. Girma and Paulson (1998) showed the existence of the seasonality in petroleum futures spreads and found trading profits arising from seasonality. Girma and Paulson (1999) found historical risk-arbitrage opportunities in petroleum futures spreads. Emery and Liu (2002) analyzed the relationship between electricity futures prices and natural-gas futures prices and reported profitably opportunities from spread trading.

Despite the empirical studies cited above, no financial model using the determinants of the profitability from futures spread trading in general, or energy futures spread trading in particular, has been presented. A profit model is needed to understand the sensitivity of the potential determinants such as mean reversion and volatility to the gains and losses from futures spread trading.

In order to examine the profitability of futures spread trading, we propose a profit model to analyze the potential of this trading strategy, focusing on how the convergence and divergence of futures spread trading generate profits and losses as represented by a stochastic process and its first hitting time probability density of price spreads. Then we apply the model to the energy futures market by modifying the general profit model to reflect the stochastic process for energy prices. We begin by modeling the price spread of energy futures using a mean-reverting process as in Dempster, Medova, and Tang (2008), which reflects the characteristics of energy futures. Then, we obtain the computable profit model by using an analytical characterization for the first hitting time density of a mean-reverting process in Linetsky (2004). The comparative static of the model 
offers an intuitive result that the future performance of the trades is enhanced by strong mean reversion and high volatility of the price spreads.

Analyzing historical performance of futures spread trading by using the energy futures prices for WTI crude oil, heating oil, and natural gas traded on the New York Mercantile Exchange (NYMEX), we find that futures spread trading can produce relatively stable profits for all three energy markets. We then investigate the principal factors impacting total profits, focusing on the characteristics of energy - seasonality, mean reversion, and volatility. Since we observe that seasonality for heating oil and natural gas affects the strategies profitability, the total profits may be determined by taking into account seasonality. More importantly, we find that high volatility in addition to long term mean reversion appear to be a key to the profitability of the trading strategy, supporting the prediction of the profit model presented in this paper.

This paper is organized as follows. Section 2 proposes a profit model for a simplified futures spread trading strategy by using a stochastic process and its first hitting time probability density. Section 3 explains how the model is modified for energy futures and investigates the potential performance of spread trading in energy futures markets. Section 4 empirically analyzes the potential value of a spread trading strategy in energy futures markets. Our conclusions are summarized in Section 5 .

\section{The Profit Model}

As explained in Section 1, spread trading involves the simultaneous purchase of one financial instrument and the sale of another financial instrument with the objective of profiting from not the movement of the absolute value of the two prices, but the movement of the spread between the two prices. The basic and most common case of spread trading involves simultaneously selling short one financial instrument with a relatively high price and buying one financial instrument with a relatively low price at the inception of the trading period, expecting that in the future the higher one will decline while the lower one will rise. If the two prices converge during the trading period, the position is closed at the time of the convergence. Otherwise, the position is forced to close at the end of the trading period. For example, suppose we denote by $P_{1, t}$ and $P_{2, t}$ the relatively high and low financial instrument prices respectively at time $t$ during the trading period. When the convergence of the price spread occurs at time $\tau$ during the trading period, the profit is the price spread at time 0 denoted by $x=P_{1,0}-P_{2,0}$. In contrast, when the price spread does not converge until the end of the trading period at time $T$, the profit stems from the difference between the spreads at times 0 and $T$ as $x-y=\left(P_{1,0}-P_{2,0}\right)-\left(P_{1, T}-P_{2, T}\right)$, where $y$ represents the price 
spread at time $T$. Thus, spread trading produces a profit or a loss from the relative price movement, not the absolute price movement. ${ }^{1}$

In this section, we present a profit model for this basic and most common spread trading strategy where the trade starts at time 0 and ends until time $T$, i.e., the trade is conducted once in the model. To do so, we need to take into account in the model (1) the price spread movement and (2) the frequency of the convergence. Here we use these basic modeling components to derive our profit model in order to formulate a general model that can be applied to spread trading regardless of the financial instrument. A stochastic process for the price spread and its first hitting time probability density are employed. Then we modify this general profit model for spread trading so that it can be applied to energy futures markets by specifying the stochastic process and the first hitting time probability density.

Let's look first at the modeling of the price spread movement. We assume that price spreads follow a stochastic process. Next, we need to capture how frequently the price spread converges. Assume that a sample path of a stochastic process with an initial value $X$ at time 0 reaches $Y$ at time $\tau$ for the first time. $\tau$ is refereed to as the "first hitting time." Here we apply it to modeling pair trading because it occurs to us that the behavior such that $X$ reaches $Y$ for the first time can help to express the convergence of price (i.e., price spread $X$ at time 0 converges on $Y=0$ at time $\tau$ ). Moreover, we believe that the corresponding probability density is useful to calculate the expected profit from the spread trading strategy. Finally, we calculate the profit from spread trading using a mean-reverting price spread model and first hitting time density for a mean-reverting process. This calculation takes into account the convergence and failure to converge of the price spread during the trading period. Consider first the case of convergence (i.e., when price spread convergence occurs which is responsible for producing the strategy's profit). In this case, the expected profit, denoted by $r_{p, c}$, is calculated as the product of price spread $x$ at time 0 and the probability for price spread convergence until the end of the trading period, because $x$ is given and fixed as an initial value. Since the spread becomes 0 from the initial value $x>0$, the first hitting time density for a stochastic process is employed. Now let's look at the case when the price spread reaches $y$ at the end of the trading period, failing to converge during the trading period. The expected profit, denoted by $r_{p, n c}$, is calculated as the integral (with respect to $y$ ) of the product of $x-y$ and the probability density for failure to converge during the trading period, resulting in the arrival at $y$ at the end of the trading period, where the probability is again obtained from the first hitting time density for a stochastic process.

\footnotetext{
${ }^{1}$ The position will be scaled such that the strategy will be self-financing. Even in this case, the price spread is relevant to the profit.
} 
Given the above, we can now derive our profit model, denoted by $r_{p}$, from a simple spread trading strategy. Suppose that $x$ is the price spread of two assets used for spread trading at time 0 when trading begins by constructing the long and short positions. First, let's consider the spread convergence case in which price spreads at times 0 and $\tau$ are fixed as $x$ and 0 , respectively. Assuming that the first hitting time density for the price spread process is $f_{\tau_{x \rightarrow 0}}(t)$, the expected return $r_{p, c}$ for this spread convergence is represented as the expectation value:

$$
r_{p, c}=x \int_{0}^{T} f_{\tau_{x \rightarrow 0}}(t) d t
$$

Next consider the case where there is a failure to converge during the trading period. This case holds if the price spread does not converge on 0 during the trading period and then reaches any price spread $y$ at the end of the trading period. Note that $y$ is greater than or equal to 0 , otherwise, the process converges on 0 before the end of the trading period. This case is represented by the difference between two events: (1) when the process with initial value of $x$ at time 0 reaches $y$ at time $T$ and (2) when it arrives at $y$ at time $T$ after the process with initial value of $x$ at time 0 converges on 0 at any time $t$ during the trading period. We denote the corresponding distribution functions by $g(y ; x, T)$ and $k(y ; x, T)$, respectively. In addition, the payoff of the trading strategy is given by $x-y$. A profit model for spread trading due to the failure to converge is expressed by the expectation value:

$$
r_{p, n c}=\int_{0}^{\infty}(x-y)\{g(y ; x, T)-k(y ; x, T)\} d y .
$$

The probability density for the latter event, $k(y ; x, T)$, is represented by the product of the first hitting time density $f_{\tau_{x \rightarrow 0}}(t)$ and the density $g(y ; 0, T-t)$, meaning that the process reaches $y$ after the first touch because both events occur independently. Since $t$ can be taken as any value during the trading period, the density function $k(y ; x, T)$ is calculated as the integral of the product with respect to $t$, as given by

$$
k(y ; x, T)=\int_{0}^{T} f_{\tau_{x \rightarrow 0}}(t) g(y ; 0, T-t) d t .
$$

A profit from spread trading for the failure to converge case is

$$
r_{p, n c}=\int_{0}^{\infty}(x-y)\left\{g(y ; x, T)-\int_{0}^{T} f_{\tau_{x \rightarrow 0}}(t) g(y ; 0, T-t) d t\right\} d y .
$$


Thus, the total profit model for spread trading is expressed by

$$
r_{p}=r_{p, c}+r_{p, n c}
$$

where $r_{p, c}$ and $r_{p, n c}$ are calculated from equations (1) and (4), respectively. Note that in reality the profit has to be compared with the transaction cost. If $r_{p}$ exceeds the cost, the actual profit is recognized.

The model is general in that it does not specify the financial instrument. In addition, the model expresses a basic and most common case for spread trading in that if price spread converges during the trading period, the profit is recognized; otherwise, the loss or profit is recognized at the end of the trading period. The profit from the trades can be easily calculated if the first hitting time probability density of the stochastic process is given.

While the profit model presented in this section applies to any financial instrument, there are nuisances when seeking to apply the model to specific sectors of the financial market that require the model be modified. In Section 3, we apply spread trading to energy futures and explain how the profit model must be modified.

\section{Modification of the Profit Model to Energy Futures Markets}

\subsection{Data}

In this study, we use the daily closing prices of WTI crude oil (WTI), heating oil (HO), and natural gas (NG) futures traded on the NYMEX. Each futures product includes six delivery months - from one month to six months. The time period covered is from April 3, 2000 to March 31, 2008. The data are obtained from Bloomberg. Summary statistics for WTI, HO, and NG futures prices are provided in Tables 1, 2, and 3, respectively. These tables indicate that WTI, HO, and NG have common skewness characteristics. The skewness of WTI, HO, and NG futures prices is positive, meaning that the distributions are skewed to the right.

[INSERT TABLE 1 ABOUT HERE]

[INSERT TABLE 2 ABOUT HERE]

[INSERT TABLE 3 ABOUT HERE] 


\subsection{The profit model for energy futures}

Figure 1 shows the term structure of the NYMEX natural gas futures, which comprise six delivery months (shown on the maturity axis) and whose daily observations cover from April 3, 2000 to March 31, 2008 (shown on the time axis). As can be seen, the shape of the futures curve with six delivery months fluctuates over the period. A closer look at Figure 1 illustrates that the futures curve sometimes exhibits backwardation (e.g., April 2002) and at other times contango (e.g., April 2004). ${ }^{2}$ The existence of backwardation and contango at different moments gives rise to the existence of the flat term structure that switches from backwardation to contango, or vice versa. Thus, energy futures prices that have different maturities converge on the flat term structure, even though price deviates from the others due to the backwardation or contango. These attributes that we observe for the term structure of energy futures prices may be useful in obtaining the potential profit in energy futures markets using the convergence of the price spread between the two correlated assets as in spread trading. More importantly, the transition of price spreads from backwardation or contango to the flat term structure can be considered as a mean reversion of the spread.

\section{[INSERT FIGURE 1 ABOUT HERE]}

In order to support this conjecture, we estimate the following autoregressive 1 lag (AR(1)) model for price spreads $\left(P^{i}-P^{j}\right)$ for $i$ and $j$ month natural gas futures $(i<j)$.

$$
P_{t}^{i}-P_{t}^{j}=C_{i j}+\rho_{i j}\left(P_{t-1}^{i}-P_{t-1}^{j}\right)+\varepsilon_{t},
$$

where $\varepsilon_{t} \sim N\left(0, \sigma_{i, j}^{2}\right)$. The results are reported in Table 4. In addition, the Phillips-Perron tests are conducted as unit root tests for stationarity not only for futures price spreads but also for each delivery month futures prices, which are shown in Tables 5 and 6, respectively.

[INSERT TABLE 4 ABOUT HERE]

[INSERT TABLE 5 ABOUT HERE]

[INSERT TABLE 6 ABOUT HERE]

As can be seen from the table, AR(1) coefficients for all combinations of the price spreads are statistically significant and greater than 0 and less than 1 . In addition, the Phillips-Perron tests

\footnotetext{
${ }^{2}$ When the futures curve increases in maturity, it is called "contango." When it decreases in maturity, it is called "backwardation."
} 
for the levels of price spreads all reject the existence of unit roots because the Phillips-Perron test statistics are less than three test critical values. Moreover comparing Table 6 with Table 5, the cointegration relationships between all two different maturity futures prices $\left(P_{i}\right.$ and $\left.P_{j}\right)$ exist with long term relationship of $P_{i}=P_{j}+$ Const because Tables 5 and 6 suggest that all futures price spreads do not have any unit root and all futures prices have one unit root, respectively. It may secure the convergence of the spread into a constant value. Given the characteristics of the price spreads for energy futures that we observe, we conclude that a mean-reverting model with long term mean can be applicable to energy futures price spreads. Hence as one of the main modification to energy futures, we try to characterize the general profit model in Section 2 irrelevant to the type of stochastic price spread process by using a mean-reverting price spread process for energy futures.

As a first-order approximation, we assume that the price spread of a spread trade, denoted by $S_{t}=P_{t}^{i}-P_{t}^{j}$, follows a mean-reverting process given by

$$
d S_{t}=\kappa\left(\theta-S_{t}\right) d t+\sigma d W_{t}
$$

Note that $\kappa=-\ln \rho_{i j}, \theta=\frac{C_{i j}}{1-\rho_{i j}}$, and $\sigma=\sigma_{i j} \sqrt{\frac{-2 \ln \rho_{i j}}{1-\rho_{i j}^{2}}}$ where we neglect the subscripts. $\kappa$ and $\theta$ represent mean reversion speed and long term mean, respectively. For simplicity, we assume that $\kappa, \theta$, and $\sigma$ are constant. Equation (7) was used by Jurek and Yang (2007) as a general formulation for an investor facing a mean-reverting arbitrage opportunity and by Dempster, Medova, and Tang (2008) for valuing and hedging spread options on two commodity prices that are assumed to be cointegrated in the long run. Since we define price spreads as the subtraction of longer maturity product price from shorter maturity product price, positive and negative spreads ( $S$ 's) demonstrate backwardation and contango, respectively. According to Table 4, the constant terms $C_{i j}$ tend to be negative, resulting in the contango in respect to long run average price spreads. For example regarding the futures price spreads between 1 - and 2- month maturities, $\theta$ is calculated as -0.163 using $C_{12}=-0.007$ and $\rho_{12}=0.957$ in Table 4 , i.e., the negative price spread which subtracts 2month product from 1- month product, resulting in the contango. Hence if the futures prices often demonstrate backwardation, the price spreads can theoretically produce profits from spread trades in the long run. In addition, taking into account that long term mean parameters $C_{i j}$ are negative but statistically insignificant except $C_{12}$ in Table 4, strong contango may also produce profits from the trades. Thus, the asymmetry in the profitability of the trading strategy depends on the statistical significance of negative long term mean parameters $\left(C_{i j}\right)$ in the long run.

As another main modification of the general model to energy futures, computable first hitting time density is employed. Linetsky (2004) provides an explicit analytical characterization for the 
first hitting time (probability) density for a mean-reverting process that can be applied to modeling interest rates, credit spreads, stochastic volatility, and convenience yields. By Proposition 2 in Linetsky (2004), the first hitting time density of a mean-reverting process moving from $x$ to 0 is approximately:

$$
f_{\tau_{x \rightarrow 0}}(t) \simeq \sum_{n=1}^{\infty} c_{n} \lambda_{n} e^{-\lambda_{n} t}
$$

where $\lambda_{n}$ and $c_{n}$ have the following large- $n$ asymptotics:

$$
\begin{aligned}
\lambda_{n} & =\kappa\left\{2 k_{n}-\frac{1}{2}\right\} \\
c_{n} & \simeq \frac{(-1)^{n+1} 2 \sqrt{k_{n}}}{\left(2 k_{n}-\frac{1}{2}\right)\left(\pi \sqrt{k_{n}}-2^{-\frac{1}{2}} \bar{y}\right)} e^{\frac{1}{4}\left(\bar{x}^{2}-\bar{y}^{2}\right)} \cos \left(\bar{x} \sqrt{2 k_{n}}-\pi k_{n}+\frac{\pi}{4}\right), \\
k_{n} & \simeq n-\frac{1}{4}+\frac{\bar{y}^{2}}{\pi^{2}}+\frac{\bar{y} \sqrt{2}}{\pi} \sqrt{n-\frac{1}{4}+\frac{\bar{y}^{2}}{2 \pi^{2}}} .
\end{aligned}
$$

$\bar{x}$ and $\bar{y}$ are expressed by

$$
\bar{x}=\frac{\sqrt{2 \kappa}}{\sigma}(x-\theta) \text { and } \bar{y}=\frac{\sqrt{2 \kappa}}{\sigma}(-\theta) .
$$

Thus, the profit model for the convergence case is modeled by

$$
r_{p, c} \simeq x \sum_{n=1}^{\infty} c_{n}\left(1-e^{-\lambda_{n} T}\right) .
$$

Next consider the case where there is a failure to converge during the trading period. Because the price spread $S_{t}$ follows a mean-reverting process, the corresponding probability density is given by

$$
g(y ; x, T)=\frac{1}{\sqrt{2 \pi} \sigma_{S}(T)} e^{-\frac{1}{2} \frac{\left(y-\mu_{S}(x, T)\right)^{2}}{\sigma_{S}(T)^{2}}},
$$

where

$$
\mu_{S}(x, T)=x e^{-\kappa T}+\theta\left(1-e^{-\kappa T}\right) \text { and } \sigma_{S}(T)=\sqrt{\frac{\sigma^{2}}{2 \kappa}\left(1-e^{-2 \kappa T}\right)} .
$$

In addition, recall that the first hitting time density for a mean-reverting process is given by equation (8). The expected profit from the failure to converge case is approximately modeled as follows:

$$
r_{p, n c} \simeq \int_{0}^{\infty}(x-y)\left\{g(y ; x, T)-\int_{0}^{T} \sum_{n=1}^{\infty} c_{n} \lambda_{n} e^{-\lambda_{n} t} g(y ; 0, T-t) d t\right\} d y
$$


Thus, the total profit model for spread trading is expressed by equation (5) where $r_{p, c}$ and $r_{p, n c}$ are calculated from equations (9) and (11), respectively.

Since both $\bar{x}$ and $\bar{y}$ embedded in the coefficients of equations (9) and (11) are expressed as functions of the mean-reversion strength and volatility of the spread, denoted by $\kappa$ and $\sigma$, respectively in equation (7), the expected profit from a simple spread trading strategy is influenced by the degree of mean reversion and volatility. More precisely, we have formulated the expected return from spread convergence and failure to converge cases using a simple mean-reverting spread model characterized by $\kappa$ and $\sigma$.

The model is not restricted to energy commodities but can be used for spread trading of other commodities such as beans and beans oil. Hence, the model can be applicable to commodities whose prices demonstrate strong mean reversion and high volatility. Because it is well known that energy prices demonstrate strong mean reversion and high volatility (see Geman (2005)), the model may fit energy commodities well.

\subsection{Comparative statics of expected return}

Since the profit model is based on a mean-reverting spread model, the expected returns are characterized by the strength of mean reversion and volatility. We conducted comparative statics of the expected return using the simple profit model we propose in equations (5), (9), and (11). As a base case, we used the following values for the parameters of equation (7): $\kappa=0.027, \theta=$ 0 , and $\sigma=0.013$, which are estimated using the WTI one- and six- month spread. Moreover, we assumed that the maturity is 120 days and $x=2 \sigma$. Based on the estimated parameters and the assumptions made, we calculated the expected return for the simple profit model $\left(r_{p}\right)$ to be 0.0140 . Thus, the model predicts that the initial spread of $x=2 \sigma=0.0260$ will produce a profit of 0.0140 from spread trading during a 120-day trading period.

We calculated the expected returns by changing the mean-reversion strength $\kappa$ and the volatility $\sigma$ in a way that one is changed and the other is fixed. First, we only increase the mean reversion $\kappa$ from 0.024 to 0.027 . As can be seen in Figure 2, the corresponding expected return increases from 0.0119 to 0.0140 . This suggests that higher mean reversion produce a higher expected return for the model. This is consistent with intuition: If mean reversion of the spread is stronger, the spread converges more immediately and the convergence generates more profit.

\section{[INSERT FIGURE 2 ABOUT HERE]}


Second, we increase the volatility $\sigma$ from 0.0112 to 0.0130 , holding mean reversion constant at 0.027 . Figure 3 shows that the return increases from 0.0114 to 0.0140 . This result suggests that higher spread volatility produces higher expected return. This is also consistent with intuition: If spread volatility is higher, the chance of spread convergence increases, resulting in a greater return. Thus, this simple comparative analysis of the influence of spread behavior on the profits suggests that stronger mean reversion and higher spread volatility may produce higher profit from a spread trading strategy. Recognizing that strong mean reversion and high spread volatility are often observed in energy markets, this suggests that a spread trading strategy applied to this market may be profitable as long as the markets are inefficient.

[INSERT FIGURE 3 ABOUT HERE]

\subsection{Future performance of spread trading in energy futures markets}

In order to examine the results in comparative statics further, we computed the expected profits using the profit model with the parameter estimates for WTI, HO, and NG one- and two- month futures, respectively. The results are reported in Table 7. $\kappa$ and $\sigma$ represent mean reversion and volatility coefficients of a mean-reverting process, respectively. The larger the $\kappa$ and $\sigma$, the higher mean reversion and volatility. According to Table 7, the mean reversion of NG futures price spreads (0.4500) is stronger than for WTI (0.0192) and HO (0.0141). In addition, the volatility of NG (0.0324) is higher than for WTI (0.0081) and HO (0.0101). On the other hand, the expected return of NG trades (0.0496) is higher than for WTI (0.0050) and HO (0.0029). Thus, the model predicts that the energy futures spread trading with the strongest mean reversion and the highest volatility for price spreads produces the highest expected return.

[INSERT TABLE 7 ABOUT HERE]

In the next section, we present our empirical findings on the spread trading strategy applied to the NYMEX energy futures market.

\section{Empirical Evidence for Energy Futures Prices}

Here we will examine historical performance of the spread trading strategy in the energy markets using the historical prices for energy futures described in Subsection 3.1. We explain the practical 
concept of spread trading using Figure 4 in accordance with Gatev, Goetzmann, and Rouwenhorst (2006). The prices are first normalized with the first day's price as in the figure, which represent the cumulative returns. A spread trading strategy involves selecting the most correlated pair of prices during the period. This period is referred to as the formation period. ${ }^{3}$ Specifically, two assets are chosen such that the standard deviation of the price spreads in the formation period is the smallest in all combinations of pairs. Then, the trade is implemented by using the selected pairs during the consecutive period, referred to as the trading period. When the price spread of the selected pairs reaches a user specified multiple of the standard deviation calculated in the formation period, a zero-cost portfolio is constructed. In our study, we specify a multiple of 2 . The zero-cost portfolio is constructed such that the higher and lower price assets are set to short and long positions, respectively. If the pairs converge during the trading period, then the positions are closed and the profit is recognized. Otherwise, the positions are forced to close and it may cause a loss from the trade. We then calculate the total profit from the trades by computing the sum of the trading gains and losses. ${ }^{4}$

\section{[INSERT FIGURE 4 ABOUT HERE]}

Now we empirically examine the profitability of spread trading in energy futures markets of WTI, HO, and NG stemming from the convergence of the different maturity futures price spreads. We discuss the source of the profitability taking into account characteristics of energy prices: seasonality, mean reversion, and volatility. Following Gatev, Goetzmann, and Rouwenhorst (2006), we set both the formation period and trading period at 120 trading days. Fifteen spreads are chosen during the formation period in order of the small standard deviation of the spreads. Then, we set 88 formation and trading periods whose starting points are determined by rolling over 20 trading days in an effort to exploit the available data effectively. ${ }^{5}$ We report the annualized profits from the WTI, HO, and NG futures trades in Figure 5. The results suggest that each trade tends to generate a profit except for trade \#25 whose trading period starts from September 3, 2002 to February 25, 2003. These findings suggest that spread trading in WTI, HO, and NG futures markets may be profitable as long as the markets are inefficient.

\section{[INSERT FIGURE 5 ABOUT HERE]}

\footnotetext{
${ }^{3}$ Since two futures contracts on the same commodity form a "natural pair," one might not think that a formation period is required for spread trading in energy futures markets. However, there are many combinations of pairs in this yield curve play. It is safe for investors to select the most correlated pairs even for two futures contracts on the same commodity. Thus, we introduce a formation period for energy futures spread trading.

${ }^{4}$ Here the spread trading allows multiple trades during the trading period as in Figure 4.

${ }^{5}$ If the first trade starts on the first trading day, the second one starts on the 21 st trading day.
} 
Having established that a pairs trading strategy is profitable, we next turn our investigation to the source of the profitability in terms of the characteristics of energy. In order to examine the influence of seasonality, mean reversion, and volatility in energy prices on the total profit, we summarized all the trades in Tables 8 and 9. Note that we refer to the total profit as the excess return because the trading gains and losses are calculated over long and short positions of one dollar and they are considered as the excess returns on the undervalue above overvalue futures as in Gatev, Goetzmann, and Rouwenhorst (2006).

\section{[INSERT TABLE 8 ABOUT HERE]}

\section{[INSERT TABLE 9 ABOUT HERE]}

In the beginning, we address the influence of seasonality of energy futures prices on the profit generated from pairs trading by focusing on winter. To do this using a simple examination, we define "winter trade" presented in Tables 8 and 9 by the trade including the days from December to February. In Tables 8 and 9, the winter trades comprise eight periods: the trades from \#1 to \#4, from \#12 to \#16, from \#25 to \#29, from \#37 to \#41, from \#50 to \#54, from \#62 to \#66, from \#75 to \#79, and from \#87 to \#88.

Table 8 shows that all winter trades of WTI, HO, and NG from \#1 to \#4 produce profits. From \#12 to \#16, the trades of HO and NG produce profits, while the trades of WTI have annualized losses of -0.36 and -0.09 for \#12 and \#13, respectively. The winter trades of WTI, HO, and NG from \#26 to \#29 produce profits. Accordingly, these findings for the winter trades suggest that while the WTI trades produce both gains and losses in the winter, the HO and NG trades always make profits in the winter. In addition, the trades of $\mathrm{HO}$ and $\mathrm{NG}$ in the summer from \#5 to \#8 and from \#17 to \#19 produce low profits or losses while the WTI trades generate profits to some extent. The same characteristics explained above are observed in the other winter trades in Tables 8 and 9. While the profits from the WTI trades are not relevant to the season, seasonality in profitability from $\mathrm{HO}$ and $\mathrm{NG}$ trades exists in the sense that the trades of $\mathrm{HO}$ and $\mathrm{NG}$ in the winter tend to cause high profits while those in the summer show low profits or losses. The results correspond to the existence of seasonality explained in Pilipovic (1998) such that HO and NG futures prices exhibit seasonality contrary to WTI futures prices.

In addition to winter trades, "NG fall trades" defined by the trade including the days from September to October tend to produce high profits: the trades from \#9 to \#12, from \#21 to \#25, from \#34 to \#37, from \#46 to \#50, from \#59 to \#62, from \#71 to \#75, and from \#84 to \#87. Hence, the NG trades may demonstrate high profits not only from winter trades but also from fall trades. 
It may imply that NG trade profits are generated not only during backwardation periods but also during contango periods because high NG demand in winter often causes backwardation while normal NG demand in fall demonstrates contango.

Since we are interested in the influence of seasonality on the total profit from energy futures pairs trading, we compared the annualized average profits between WTI, HO, and NG. According to the results reported in Table 9, the profits from six WTI, HO, and NG futures trades are 0.61, 0.74 , and 3.15, respectively. We found that the NG trading generates the largest total profits (i.e., the highest excess return) of the three contracts investigated during the trading periods as in Table 9, while the HO and the WTI showed the second and the third highest excess return, respectively. Since the profits from the WTI trades without seasonality are less than those from the HO and NG trades with seasonality, this factor may determine the total profit.

Next, we can shed light on the mean reversion and volatility of the spread as the source of the total profits from spread trading. For all combinations of the spreads for each energy futures, we estimate the parameters of $\operatorname{AR}(1)$ coefficient $\rho$ and standard deviation $\sigma$, which represent meanreversion strength and volatility, respectively, using equation (6). Then, we take the average $\bar{\rho}$ and $\bar{\sigma}$ of the estimated $\rho$ 's and $\sigma$ 's, respectively, in order to capture the average trend of the mean reversion and volatility of each energy futures market. The results are shown in Table 10. As can be seen, the price spread of NG futures has the highest volatility of the three, because the standard deviation is the largest (0.257) of the three. In addition while all three futures price spreads demonstrate long term mean reversion, mean reversion of natural gas futures price spreads is the strongest of the three. Considering that the NG trades generate the highest average return (3.15) of the three, the highest total profit of spread trading applied to NG futures may come from the highest volatility of the spread in addition to its long term mean reversion. The riskadjusted measure of performance is more persuasive in order to judge the performance. Thus, we also calculated the risk-adjusted returns assuming a risk-free rate of $4 \%$ in Table 11 where mean and standard deviation of returns are obtained from the results of Tables 8 and 9. Similar to the average returns, the NG trades are more profitable than the others in terms of a risk-adjusted measure of performance because the Sharpe ratio of the NG trades (1.07) is larger than those of WTI (0.56) and HO (0.55). Thus, the highest risk-adjusted return of spread trading using NG futures may also stem from the long term mean reversion and highest volatility of the spread. Recalling that the comparative statics and future performance of spread trading in Subsections 3.3 and 3.4, respectively suggested that the long term mean reversion and high volatility of price spreads may produce high performance of spread trading as long as the markets are inefficient, the results in this section are consistent with the results from the comparative static analysis and future performance of spread trading. 


\section{[INSERT TABLE 10 ABOUT HERE]}

\section{[INSERT TABLE 11 ABOUT HERE]}

Finally in order to enhance the importance of price spread volatility for the trade profitability, we apply a regime-switching model to NG futures price spreads where two regimes have different volatility of $\sigma_{1}$ and $\sigma_{2}$, respectively and each process has mean reversion. Here we assume that the state variable $s_{t}$ evolves according to a first-order Markov chain, with transition probability $\operatorname{Pr}\left(s_{t}=j \mid s_{t-1}=i\right)=p_{i j}$. It indicates the probability of regime switching from state $i$ at time $t-1$ to state $j$ at time $t$. These probabilities are rewritten in the transition matrix:

$$
P=\left(\begin{array}{ll}
p_{11} & p_{21} \\
p_{21} & p_{22}
\end{array}\right)=\left(\begin{array}{cc}
p_{11} & 1-p_{22} \\
1-p_{11} & p_{22}
\end{array}\right)
$$

The regime switching model can be written as

$$
S_{t}=\left\{\begin{array}{l}
\phi_{0,1}+\phi_{1,1} S_{t-1}+\varepsilon_{t}^{1} \\
\phi_{0,2}+\phi_{1,2} S_{t-1}+\varepsilon_{t}^{2}
\end{array}\right.
$$

where $\varepsilon_{t}^{i} \sim N\left(0, \sigma_{i}^{2}\right)$. We estimate the parameters of this model using 1- and 2-month NG futures price spreads. The usual maximum likelihood method is applied by following e.g., Hamilton (1994). The results are reported in Table 12. The parameters except $\phi_{0,2}$ and $\phi_{1,2}$ are statistically significant. Taking into account that $\sigma_{2}$ is greater than $\sigma_{1}$, the state 1 and state 2 correspond to low and high volatility regimes, respectively. In addition, Figure 6 plots the smoothed probabilities of high volatility regime using Kim (1993), corresponding price spreads, and spread changes. It reports that high volatility regime tends to stand on high price spread and high spread change periods, e.g., January 2001, October 2004, October 2005, and September 2006. Looking back to Tables 8 and 9, it is observed that the NG trades during these high volatility regime periods tend to produce high profits. For example, the trade \#2 with high NG profit of 8.02 in Table 8 includes high volatility regime period of January 2001. Similarly high NG trade profits from trades \#50 (10.26), \#61 (10.41), and \#71 (8.59) and \#73 (10.61) are obtained in high volatility regime periods corresponding to October 2004, October 2005, and September 2006, respectively. Hence, the results may also support our discussion such that high volatility produces high profit from the trades. In addition, according to the middle picture of Figure 6, the profitable period of January 2001 demonstrates backwardation because of positive price spreads while the other profitable periods like October 2004 demonstrate contango. Hence both of backwardation and contango seem to produce profits from NG trades. Furthermore, since $\phi_{1,2}$ is less than one but 
statistically insignificant, the long term mean reversion may diminish during the high volatility state period. It may imply that high volatility does not necessarily coincide with long term mean reversion.

\section{[INSERT TABLE 12 ABOUT HERE]}

\section{[INSERT FIGURE 6 ABOUT HERE]}

As is discussed, the results from the empirical analyses document that the long term mean reversion and high volatility of price spreads may influence the total profit from spread trading of energy futures, resulting in the support for the profit model we proposed in this paper.

\section{Conclusions}

In this paper, we provide a profit model for spread trading by focusing on the stochastic movement of the price spread and its first hitting time probability density. The model is general in that it does not specify the financial instrument. The advantage of the model is that the profit from the trades can be easily calculated if the first hitting time probability density of the stochastic process is given. Then the model was modified to fit energy futures by using a mean-reverting process of the spreads, which reflects the characteristics of energy futures, with the computable first hitting time density. The model predicted that future performance of pairs trading was enhanced by strong mean reversion and high volatility of the price spreads. Our empirical analyses using WTI crude oil, heating oil, and natural gas futures traded on the NYMEX show that pairs trading in energy futures markets could produce a relatively stable profit in the past. Then, the sources of the total profit were investigated from the characteristics of energy futures prices: seasonality, mean reversion, and volatility. The total profits from heating oil and natural gas trading were found to be positively affected by seasonality, contrary to the WTI crude oil, resulting in greater total profits of heating oil and natural gas with seasonality than that of WTI crude oil without seasonality. Seasonality may seem to characterize the total profit. More importantly, we examined the influence of mean reversion and volatility of price spreads on the total profit. The results suggest that the high volatility in addition to the long term mean reversion may cause high total profits from pairs trading, especially in natural gas trades, which offers supportive evidence of the model prediction.

The spread trading between energy commodity futures and their derivatives can be conducted due to the influence of an increasing speculative tendency in the market e.g., for crude oil and 
its derivatives. However this paper only dealt with the spread trading between different maturity products for a single commodity due to the availability of the data. We leave this discussion for our future research. 


\section{References}

Dempster, M., E. Medova, and K. Tang, 2008, Long term spread option valuation and hedging, Journal of Banking and Finance 32, 2530-2540.

Emery, G. W., and Q. Liu, 2002, An analysis of the relationship between electricity and natural-gas futures prices, Journal of Futures Markets 22, 95-122.

Gatev, E.G., W. N. Goetzmann, and K. G. Rouwenhorst, 2006, Pairs trading: Performance of a relative-value arbitrage rule, Review of Financial Studies 19, 797-827.

Geman, H., 2005, Commodities and Commodity Derivatives. (John Wiley \& Sons Ltd West Sussex).

Girma, P. B., and A. S. Paulson, 1998, Seasonality in petroleum futures spreads, Journal of Futures Markets $18,581-598$.

Girma, P. B., and A. S. Paulson, 1999, Risk arbitrage opportunities in petroleum futures spreads, Journal of Futures Markets 19, 931-955.

Hamilton, J. D., 1994, Time Series Analysis. (Princeton University Press Princeton).

Jurek, J., and H. Yang, 2007, Dynamic portfolio selection in arbitrage, Working paper, Harvard University.

Kim, C. J., 1993, Dynamic linear models with Markov-Switching, Journal of Econometrics 1, 1-22.

Linetsky, V., 2004, Computing hitting time densities for CIR and OU diffusions: Applications to meanreverting models, Journal of Computational Finance 7, 1-22.

Pilipovic, D., 1998, Energy Risk: Valuing and Managing Energy Derivatives. (McGraw-Hill New York). 


\section{Figures \& Tables}

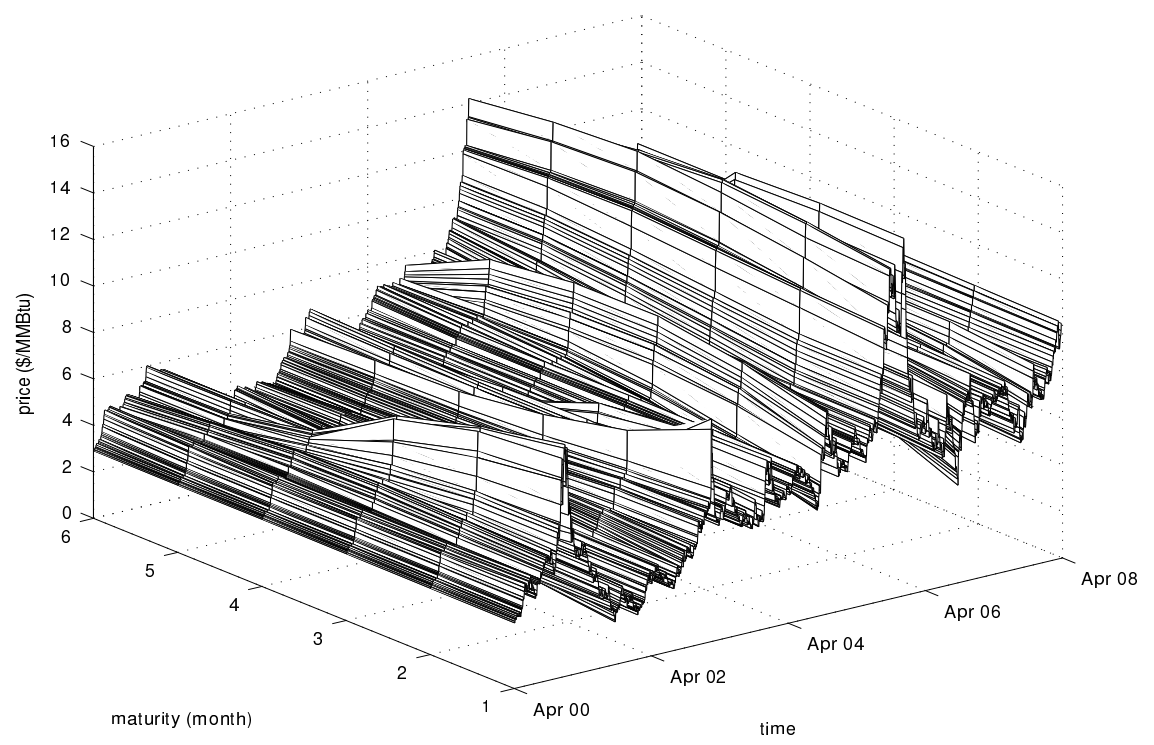

Figure 1. NYMEX Natural Gas Futures Curves

April 3, 2000 - March 31, 2008. NG futures product includes six delivery months - from one to six months. 


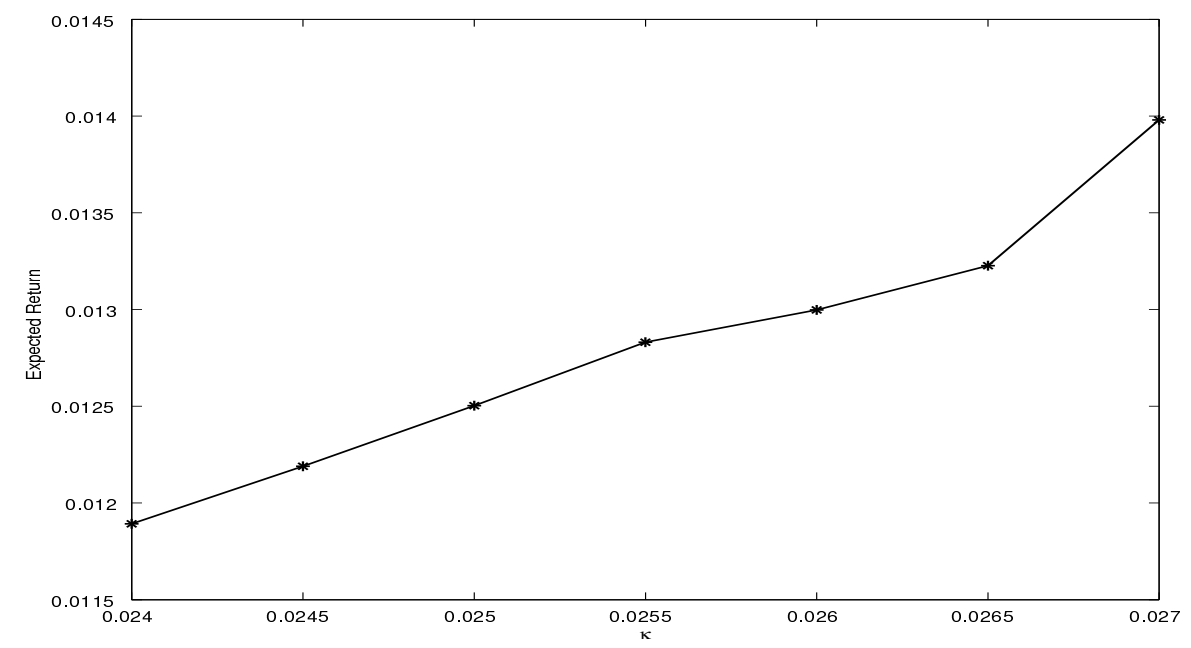

Figure 2. Comparative Statics of $\kappa$

By increasing the mean-reversion parameter $\kappa$ from 0.024 to 0.027 holding volatility constant at 0.0130 , the corresponding expected returns for the simple profit model are shown.

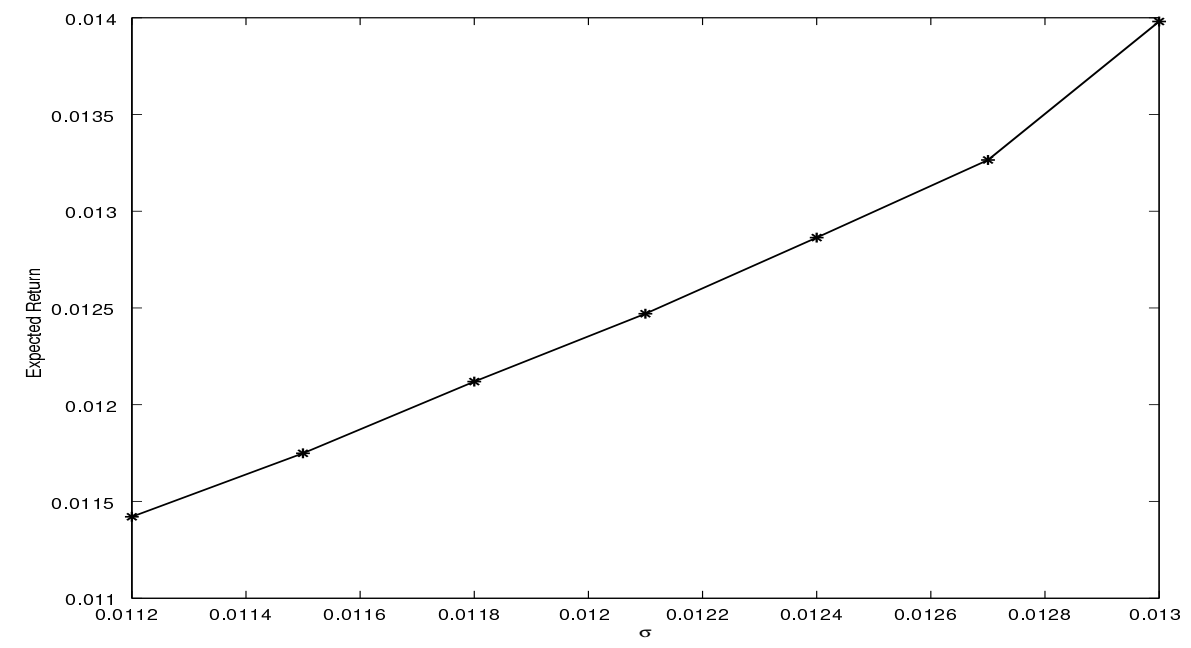

Figure 3. Comparative Statics of $\sigma$

By increasing the volatility parameter $\sigma$ from 0.0112 to 0.0130 holding mean reversion constant at 0.027 , the corresponding expected returns for the simple profit model are shown. 


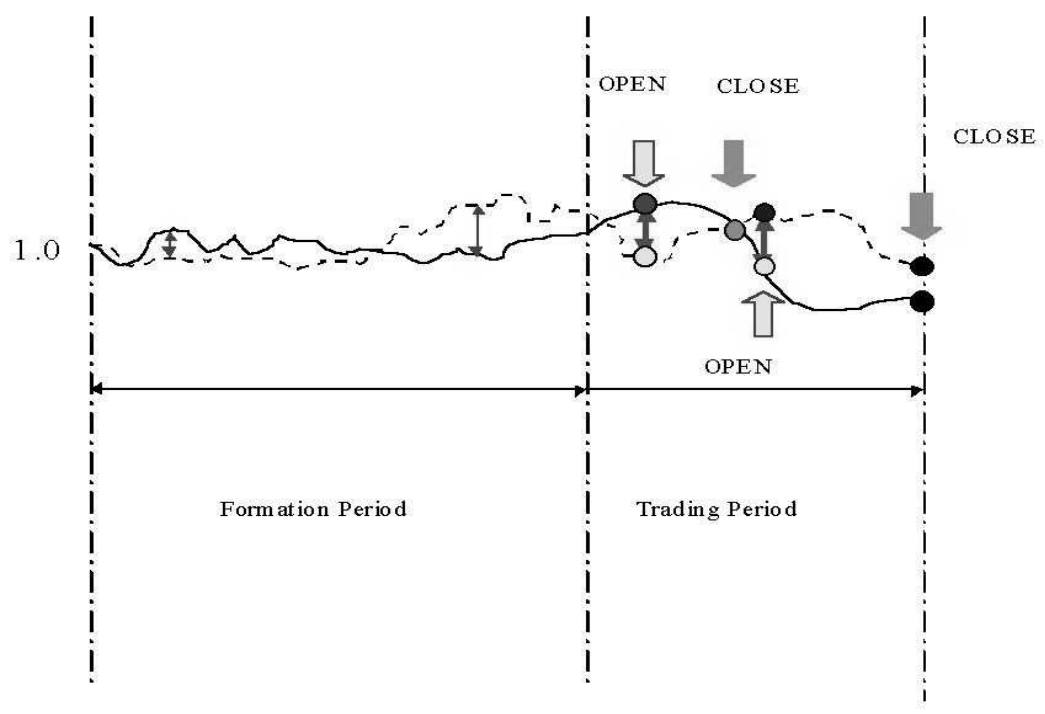

Figure 4. Spread Trading

The prices are first normalized with the first day's price as in the figure. A spread trading strategy involves selecting the most correlated pair of prices during the period. This period is referred to as the formation period. Then, the trade is implemented by using the selected pairs during the next period, referred to as the trading period. When the price spread of the selected pairs reaches a user specified multiple of the standard deviation calculated in the formation period, a zero-cost portfolio is constructed. If the pairs converge during the trading period, then the positions are closed. Otherwise, the positions are forced to close. 


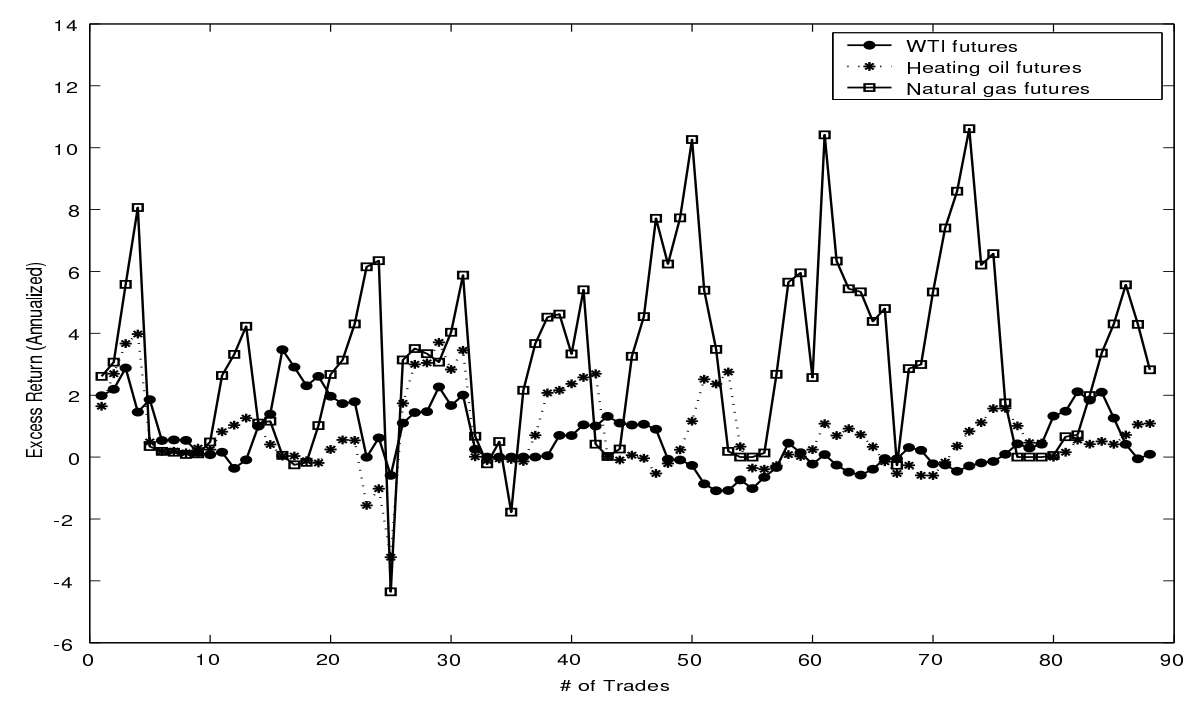

Figure 5. Spread Trading of WTI Crude Oil, Heating Oil, and Natural Gas Futures

We set 88 formation and trading periods whose starting points are determined by rolling 20 trading days. The first starting point is September 25, 2000 and the last (88th) point is September 14, 2007.
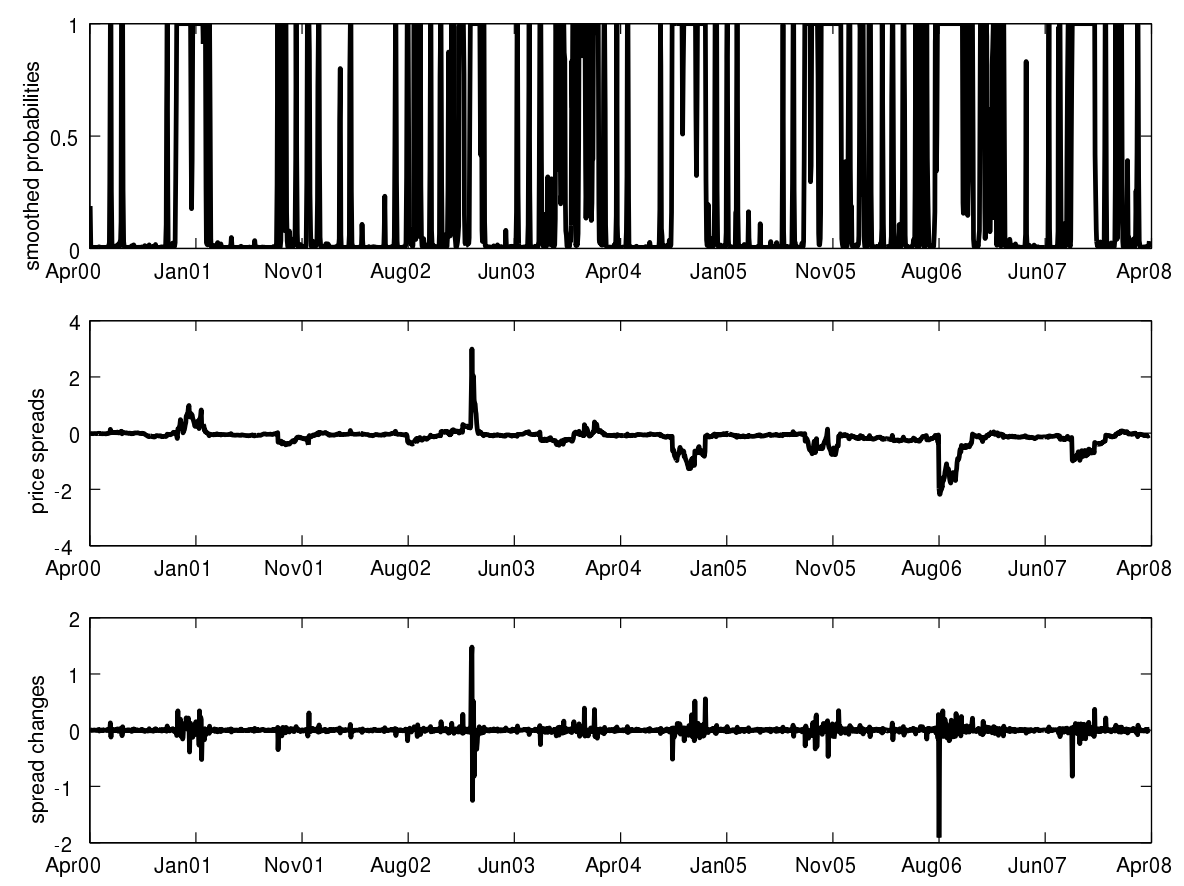

Figure 6. Smoothed Probabilities for High Volatility Regime, Price Spreads, and Spread Changes 1- and 2- month NG futures price spreads are used for these figures. 


\begin{tabular}{lrrrrrr}
\hline & \multicolumn{1}{c}{$\mathrm{WTI}_{1}$} & \multicolumn{1}{c}{$\mathrm{WTI}_{2}$} & \multicolumn{1}{c}{$\mathrm{WTI}_{3}$} & \multicolumn{1}{c}{$\mathrm{WTI}_{4}$} & $\mathrm{WTI}_{5}$ & \multicolumn{1}{c}{$\mathrm{WTI}_{6}$} \\
\hline Mean & 45.96 & 46.03 & 45.99 & 45.87 & 45.71 & 45.55 \\
Median & 37.21 & 36.47 & 35.91 & 35.44 & 34.99 & 34.53 \\
Maximum & 110.33 & 109.17 & 107.94 & 106.90 & 106.06 & 105.44 \\
Minimum & 17.45 & 17.84 & 18.06 & 18.27 & 18.44 & 18.60 \\
Std. Dev. & 20.66 & 20.92 & 21.14 & 21.32 & 21.49 & 21.65 \\
Skewness & 0.81 & 0.76 & 0.72 & 0.69 & 0.67 & 0.66 \\
Kurtosis & 2.79 & 2.59 & 2.44 & 2.33 & 2.24 & 2.17 \\
\hline
\end{tabular}

Table 1. Basic Statistics of WTI Crude Oil Futures Prices

April 3, 2000 - March 31, 2008. The maturity month is denoted by a subindex from one to six months.

\begin{tabular}{lrrrrrr}
\hline & \multicolumn{1}{c}{$\mathrm{HO}_{1}$} & \multicolumn{1}{c}{$\mathrm{HO}_{2}$} & \multicolumn{1}{c}{$\mathrm{HO}_{3}$} & \multicolumn{1}{c}{$\mathrm{HO}_{4}$} & \multicolumn{1}{c}{$\mathrm{HO}_{5}$} & \multicolumn{1}{c}{$\mathrm{HO}_{6}$} \\
\hline Mean & 127.86 & 128.27 & 128.35 & 128.15 & 127.82 & 127.44 \\
Median & 101.90 & 99.83 & 98.53 & 96.25 & 94.02 & 91.97 \\
Maximum & 314.83 & 306.45 & 301.55 & 301.05 & 301.10 & 301.50 \\
Minimum & 49.99 & 51.31 & 51.71 & 51.96 & 51.52 & 50.87 \\
Std. Dev. & 59.54 & 60.28 & 60.98 & 61.52 & 61.93 & 62.30 \\
Skewness & 0.73 & 0.68 & 0.65 & 0.64 & 0.63 & 0.62 \\
Kurtosis & 2.58 & 2.37 & 2.21 & 2.11 & 2.04 & 2.00 \\
\hline
\end{tabular}

Table 2. Basic Statistics of Heating Oil Futures Prices

April 3, 2000 - March 31, 2008. The maturity month is denoted by a subindex from one to six months.

\begin{tabular}{lrrrrrr}
\hline & $\mathrm{NG}_{1}$ & $\mathrm{NG}_{2}$ & $\mathrm{NG}_{3}$ & $\mathrm{NG}_{4}$ & $\mathrm{NG}_{5}$ & $\mathrm{NG}_{6}$ \\
\hline Mean & 6.01 & 6.16 & 6.27 & 6.31 & 6.35 & 6.36 \\
Median & 5.94 & 6.11 & 6.19 & 6.09 & 6.11 & 6.18 \\
Maximum & 15.38 & 15.43 & 15.29 & 14.91 & 14.67 & 14.22 \\
Minimum & 1.83 & 1.98 & 2.08 & 2.18 & 2.26 & 2.33 \\
Std. Dev. & 2.27 & 2.32 & 2.36 & 2.34 & 2.33 & 2.30 \\
Skewness & 0.90 & 0.90 & 0.90 & 0.73 & 0.60 & 0.39 \\
Kurtosis & 4.75 & 4.72 & 4.57 & 3.83 & 3.28 & 2.43 \\
\hline
\end{tabular}

Table 3. Basic Statistics of Natural Gas Futures Prices

April 3, 2000 - March 31, 2008. The maturity month is denoted by a subindex from one to six months. 


\begin{tabular}{lcccccccccc}
\hline Variable & $C_{12}$ & $\rho_{12}$ & $C_{13}$ & $\rho_{13}$ & $C_{14}$ & $\rho_{14}$ & $C_{15}$ & $\rho_{15}$ & $C_{16}$ & $\rho_{16}$ \\
\hline Coefficient & -0.007 & 0.957 & -0.006 & 0.977 & -0.005 & 0.985 & -0.004 & 0.987 & -0.004 & 0.989 \\
Std. Error & 0.003 & 0.015 & 0.004 & 0.011 & 0.005 & 0.008 & 0.005 & 0.007 & 0.005 & 0.006 \\
\hline Variable & $C_{23}$ & $\rho_{23}$ & $C_{24}$ & $\rho_{24}$ & $C_{25}$ & $\rho_{25}$ & $C_{26}$ & $\rho_{26}$ & $C_{34}$ & $\rho_{34}$ \\
\hline Coefficient & -0.003 & 0.976 & -0.002 & 0.985 & -0.003 & 0.987 & -0.002 & 0.989 & -0.001 & 0.980 \\
Std. Error & 0.002 & 0.012 & 0.004 & 0.009 & 0.004 & 0.007 & 0.004 & 0.006 & 0.003 & 0.018 \\
\hline Variable & $C_{35}$ & $\rho_{35}$ & $C_{36}$ & $\rho_{36}$ & $C_{45}$ & $\rho_{45}$ & $C_{46}$ & $\rho_{46}$ & $C_{56}$ & $\rho_{56}$ \\
\hline Coefficient & -0.001 & 0.984 & -0.001 & 0.987 & -0.001 & 0.976 & -0.001 & 0.986 & 0.000 & 0.973 \\
Std. Error & 0.004 & 0.011 & 0.004 & 0.007 & 0.002 & 0.012 & 0.003 & 0.007 & 0.003 & 0.018 \\
\hline
\end{tabular}

Table 4. AR(1) Models for Natural Gas Futures Price Spread

$C_{i j}$ and $\rho_{i j}$ denote the constant term and the first lag coefficient of $\operatorname{AR}(1)$ model for price spreads $\left(P^{i}-P^{j}\right)$ for $i$ and $j$ month natural gas futures $(i<j)$.

\begin{tabular}{lrrrr}
\hline & Phillips-Perron test statistic & \multicolumn{3}{c}{ Test critical values: } \\
& & 1\% level & $5 \%$ level & $10 \%$ level \\
\hline $\mathrm{NG}_{12}$ & -6.498 & -3.433 & -2.863 & -2.567 \\
$\mathrm{NG}_{13}$ & -4.701 & -3.433 & -2.863 & -2.567 \\
$\mathrm{NG}_{14}$ & -4.371 & -3.433 & -2.863 & -2.567 \\
$\mathrm{NG}_{15}$ & -3.706 & -3.433 & -2.863 & -2.567 \\
$\mathrm{NG}_{16}$ & -3.477 & -3.433 & -2.863 & -2.567 \\
$\mathrm{NG}_{23}$ & -4.733 & -3.433 & -2.863 & -2.567 \\
$\mathrm{NG}_{24}$ & -4.548 & -3.433 & -2.863 & -2.567 \\
$\mathrm{NG}_{25}$ & -3.834 & -3.433 & -2.863 & -2.567 \\
$\mathrm{NG}_{26}$ & -3.492 & -3.433 & -2.863 & -2.567 \\
$\mathrm{NG}_{34}$ & -5.513 & -3.433 & -2.863 & -2.567 \\
$\mathrm{NG}_{35}$ & -4.479 & -3.433 & -2.863 & -2.567 \\
$\mathrm{NG}_{36}$ & -3.938 & -3.433 & -2.863 & -2.567 \\
$\mathrm{NG}_{45}$ & -4.916 & -3.433 & -2.863 & -2.567 \\
$\mathrm{NG}_{46}$ & -4.002 & -3.433 & -2.863 & -2.567 \\
$\mathrm{NG}_{56}$ & -5.487 & -3.433 & -2.863 & -2.567 \\
\hline
\end{tabular}

Table 5. Phillips-Perron Test for Futures Price Spreads

Here the subscripts represent two maturity months used for futures price spreads. Phillips-Perron tests for the level of all price spreads are conducted. If a test statistic is less than test critical values, the null hypothesis such that unit root exists is rejected, resulting in the existence of mean reversion. 


\begin{tabular}{llrrrr}
\hline $\begin{array}{l}\text { Test for unit } \\
\text { root in }\end{array}$ & $\begin{array}{c}\text { Maturity } \\
\text { Month }\end{array}$ & $\begin{array}{l}\text { Phillips-Perron } \\
\text { test statistic }\end{array}$ & \multicolumn{2}{l}{ Test critical values: } \\
1\% level & & 5\% level & 10\% level \\
\hline Level & $\mathrm{NG}_{1}$ & -2.367 & -3.433 & -2.863 & -2.567 \\
& $\mathrm{NG}_{2}$ & -2.115 & -3.433 & -2.863 & -2.567 \\
& $\mathrm{NG}_{3}$ & -2.039 & -3.433 & -2.863 & -2.567 \\
& $\mathrm{NG}_{4}$ & -1.680 & -3.433 & -2.863 & -2.567 \\
& $\mathrm{NG}_{5}$ & -1.668 & -3.433 & -2.863 & -2.567 \\
& $\mathrm{NG}_{6}$ & -1.424 & -3.433 & -2.863 & -2.567 \\
\hline First Difference & $\mathrm{NG}_{1}$ & -44.392 & -3.433 & -2.863 & -2.567 \\
& $\mathrm{NG}_{2}$ & -45.718 & -3.433 & -2.863 & -2.567 \\
& $\mathrm{NG}_{3}$ & -44.534 & -3.433 & -2.863 & -2.567 \\
& $\mathrm{NG}_{4}$ & -44.332 & -3.433 & -2.863 & -2.567 \\
& $\mathrm{NG}_{5}$ & -43.583 & -3.433 & -2.863 & -2.567 \\
& $\mathrm{NG}_{6}$ & -46.471 & -3.433 & -2.863 & -2.567 \\
\hline
\end{tabular}

Table 6. Phillips-Perron Test for Futures Prices

Here the subscripts of NG represent maturity month. Phillips-Perron tests for the level and the first difference are conducted. If a test statistic is less than test critical values, the null hypothesis such that unit root exists is rejected.

\begin{tabular}{lccr}
\hline & $\kappa$ & $\sigma$ & Expected Profit \\
\hline WTI Futures & 0.0192 & 0.0081 & 0.0050 \\
Heating Oil Futures & 0.0141 & 0.0101 & 0.0029 \\
Natural Gas Futures & 0.0450 & 0.0327 & 0.0496 \\
\hline
\end{tabular}

Table 7. Expected Profit based on Model

The parameters of $\kappa$ and $\sigma$ are estimated using 1- and 2-month futures prices. 


\begin{tabular}{|c|c|c|c|c|c|c|}
\hline$\#$ & Beginning & End & WTI & $\mathrm{HO}$ & $\mathrm{NG}$ & Winter Trade \\
\hline 1 & $09 / 25 / 00$ & $03 / 19 / 01$ & 1.98 & 1.64 & 2.61 & Yes \\
\hline 2 & $10 / 23 / 00$ & $04 / 17 / 01$ & 2.19 & 2.70 & 3.07 & Yes \\
\hline 3 & $11 / 20 / 00$ & $05 / 15 / 01$ & 2.88 & 3.67 & 5.58 & Yes \\
\hline 4 & $12 / 20 / 00$ & 06/13/01 & 1.45 & 3.98 & 8.06 & Yes \\
\hline 5 & $01 / 22 / 01$ & $07 / 12 / 01$ & 1.85 & 0.49 & 0.34 & No \\
\hline 6 & 02/20/01 & 08/09/01 & 0.53 & 0.19 & 0.18 & No \\
\hline 7 & $03 / 20 / 01$ & 09/07/01 & 0.55 & 0.19 & 0.16 & No \\
\hline 8 & $04 / 18 / 01$ & $10 / 11 / 01$ & 0.54 & 0.14 & 0.08 & No \\
\hline 9 & $05 / 16 / 01$ & $11 / 08 / 01$ & 0.15 & 0.29 & 0.11 & No \\
\hline 10 & $06 / 14 / 01$ & $12 / 10 / 01$ & 0.08 & 0.24 & 0.49 & No \\
\hline 11 & $07 / 13 / 01$ & 01/10/02 & 0.16 & 0.82 & 2.64 & No \\
\hline 12 & 08/10/01 & $02 / 08 / 02$ & -0.36 & 1.03 & 3.32 & Yes \\
\hline 13 & 09/10/01 & $03 / 11 / 02$ & -0.09 & 1.26 & 4.23 & Yes \\
\hline 14 & $10 / 12 / 01$ & $04 / 09 / 02$ & 1.00 & 1.01 & 1.10 & Yes \\
\hline 15 & $11 / 09 / 01$ & $05 / 07 / 02$ & 1.39 & 0.41 & 1.16 & Yes \\
\hline 16 & $12 / 11 / 01$ & 06/05/02 & 3.47 & 0.03 & 0.06 & Yes \\
\hline 17 & $01 / 11 / 02$ & $07 / 03 / 02$ & 2.90 & 0.03 & -0.25 & No \\
\hline 18 & $02 / 11 / 02$ & 08/02/02 & 2.30 & -0.12 & -0.17 & No \\
\hline 19 & $03 / 12 / 02$ & 08/30/02 & 2.61 & -0.19 & 1.02 & No \\
\hline 20 & $04 / 10 / 02$ & 09/30/02 & 1.96 & 0.25 & 2.67 & No \\
\hline 21 & 05/08/02 & $10 / 28 / 02$ & 1.73 & 0.56 & 3.14 & No \\
\hline 22 & $06 / 06 / 02$ & $11 / 25 / 02$ & 1.79 & 0.54 & 4.30 & No \\
\hline 23 & $07 / 08 / 02$ & $12 / 26 / 02$ & -0.01 & -1.56 & 6.15 & No \\
\hline 24 & 08/05/02 & $01 / 27 / 03$ & 0.62 & -1.02 & 6.35 & No \\
\hline 25 & 09/03/02 & $02 / 25 / 03$ & -0.59 & -3.24 & -4.35 & Yes \\
\hline 26 & $10 / 01 / 02$ & $03 / 25 / 03$ & 1.10 & 1.74 & 3.14 & Yes \\
\hline 27 & $10 / 29 / 02$ & $04 / 23 / 03$ & 1.44 & 3.00 & 3.51 & Yes \\
\hline 28 & $11 / 26 / 02$ & $05 / 21 / 03$ & 1.47 & 3.04 & 3.34 & Yes \\
\hline 29 & $12 / 27 / 02$ & $06 / 19 / 03$ & 2.27 & 3.71 & 3.07 & Yes \\
\hline 30 & $01 / 28 / 03$ & $07 / 18 / 03$ & 1.67 & 2.83 & 4.03 & No \\
\hline 31 & $02 / 26 / 03$ & $08 / 15 / 03$ & 2.00 & 3.45 & 5.88 & No \\
\hline 32 & $03 / 26 / 03$ & $09 / 15 / 03$ & 0.25 & 0.01 & 0.67 & No \\
\hline 33 & $04 / 24 / 03$ & $10 / 13 / 03$ & 0.00 & -0.11 & -0.22 & No \\
\hline 34 & $05 / 22 / 03$ & $11 / 10 / 03$ & 0.00 & -0.06 & 0.50 & No \\
\hline 35 & $06 / 20 / 03$ & $12 / 10 / 03$ & 0.00 & -0.08 & -1.78 & No \\
\hline 36 & $07 / 21 / 03$ & $01 / 13 / 04$ & 0.00 & -0.14 & 2.16 & No \\
\hline 37 & 08/18/03 & $02 / 11 / 04$ & 0.00 & 0.71 & 3.67 & Yes \\
\hline 38 & 09/16/03 & $03 / 11 / 04$ & 0.04 & 2.08 & 4.52 & Yes \\
\hline 39 & $10 / 14 / 03$ & 04/08/04 & 0.70 & 2.16 & 4.62 & Yes \\
\hline 40 & $11 / 11 / 03$ & $05 / 07 / 04$ & 0.70 & 2.37 & 3.33 & Yes \\
\hline 41 & $12 / 11 / 03$ & $06 / 07 / 04$ & 1.04 & 2.57 & 5.40 & Yes \\
\hline 42 & $01 / 14 / 04$ & 07/07/04 & 1.01 & 2.69 & 0.41 & No \\
\hline 43 & $02 / 13 / 04$ & 08/04/04 & 1.32 & 0.02 & 0.02 & No \\
\hline 44 & $03 / 12 / 04$ & $09 / 01 / 04$ & 1.10 & -0.10 & 0.26 & No \\
\hline 45 & $04 / 12 / 04$ & 09/30/04 & 1.04 & 0.06 & 3.26 & No \\
\hline
\end{tabular}

Table 8. Excess Returns from Pairs Trading and Seasonality

"Winter trade" is defined to be trades including the days from December to February. The winter trades in this table comprise four periods: the trades from \#1 to \#4, from \#12 to \#16, from \#25 to \#29, and from \#37 to \#41. 


\begin{tabular}{|c|c|c|c|c|c|c|}
\hline \# & Beginning & End & WTI & $\mathrm{HO}$ & $\mathrm{NG}$ & Winter Trade \\
\hline 46 & $05 / 10 / 04$ & $10 / 28 / 04$ & 1.06 & -0.04 & 4.54 & No \\
\hline 47 & 06/08/04 & $11 / 29 / 04$ & 0.90 & -0.53 & 7.72 & No \\
\hline 48 & 07/08/04 & $12 / 28 / 04$ & -0.07 & -0.21 & 6.24 & No \\
\hline 49 & 08/05/04 & $01 / 27 / 05$ & -0.09 & 0.24 & 7.73 & No \\
\hline 50 & 09/02/04 & $02 / 25 / 05$ & -0.27 & 1.16 & 10.26 & Yes \\
\hline 51 & 10/01/04 & $03 / 28 / 05$ & -0.87 & 2.51 & 5.39 & Yes \\
\hline 52 & $10 / 29 / 04$ & $04 / 25 / 05$ & -1.09 & 2.36 & 3.48 & Yes \\
\hline 53 & $11 / 30 / 04$ & $05 / 23 / 05$ & -1.08 & 2.75 & 0.19 & Yes \\
\hline 54 & $12 / 29 / 04$ & $06 / 21 / 05$ & -0.74 & 0.34 & 0.00 & Yes \\
\hline 55 & 01/28/05 & $07 / 20 / 05$ & -1.02 & -0.36 & 0.00 & No \\
\hline 56 & 02/28/05 & $08 / 17 / 05$ & -0.65 & -0.39 & 0.13 & No \\
\hline 57 & 03/29/05 & 09/15/05 & -0.33 & -0.28 & 2.68 & No \\
\hline 58 & $04 / 26 / 05$ & $10 / 13 / 05$ & 0.45 & 0.08 & 5.65 & No \\
\hline 59 & $05 / 24 / 05$ & $11 / 10 / 05$ & 0.14 & 0.02 & 5.96 & No \\
\hline 60 & $06 / 22 / 05$ & $12 / 12 / 05$ & -0.23 & 0.24 & 2.57 & No \\
\hline 61 & $07 / 21 / 05$ & 01/11/06 & 0.08 & 1.08 & 10.41 & No \\
\hline 62 & 08/18/05 & 02/09/06 & -0.26 & 0.70 & 6.33 & Yes \\
\hline 63 & 09/16/05 & 03/10/06 & -0.49 & 0.92 & 5.44 & Yes \\
\hline 64 & $10 / 14 / 05$ & 04/07/06 & -0.58 & 0.73 & 5.34 & Yes \\
\hline 65 & $11 / 11 / 05$ & 05/08/06 & -0.39 & 0.33 & 4.38 & Yes \\
\hline 66 & $12 / 13 / 05$ & 06/06/06 & -0.05 & -0.15 & 4.80 & Yes \\
\hline 67 & 01/12/06 & 07/05/06 & -0.06 & -0.53 & -0.26 & No \\
\hline 68 & 02/10/06 & $08 / 02 / 06$ & 0.31 & -0.26 & 2.86 & No \\
\hline 69 & 03/13/06 & 08/30/06 & 0.22 & -0.59 & 2.99 & No \\
\hline 70 & 04/10/06 & $09 / 28 / 06$ & -0.22 & -0.60 & 5.34 & No \\
\hline 71 & 05/09/06 & $10 / 26 / 06$ & -0.26 & -0.17 & 7.40 & No \\
\hline 72 & 06/07/06 & $11 / 24 / 06$ & -0.46 & 0.36 & 8.59 & No \\
\hline 73 & 07/06/06 & $12 / 22 / 06$ & -0.29 & 0.83 & 10.61 & No \\
\hline 74 & 08/03/06 & $01 / 25 / 07$ & -0.19 & 1.11 & 6.20 & No \\
\hline 75 & 08/31/06 & $02 / 23 / 07$ & -0.14 & 1.57 & 6.58 & Yes \\
\hline 76 & 09/29/06 & 03/23/07 & 0.09 & 1.58 & 1.75 & Yes \\
\hline 77 & $10 / 27 / 06$ & $04 / 23 / 07$ & 0.43 & 1.01 & 0.00 & Yes \\
\hline 78 & $11 / 27 / 06$ & $05 / 21 / 07$ & 0.30 & 0.47 & 0.00 & Yes \\
\hline 79 & $12 / 26 / 06$ & 06/19/07 & 0.42 & 0.45 & 0.00 & Yes \\
\hline 80 & $01 / 26 / 07$ & 07/18/07 & 1.33 & 0.00 & 0.05 & No \\
\hline 81 & 02/26/07 & 08/15/07 & 1.48 & 0.16 & 0.66 & No \\
\hline 82 & 03/26/07 & 09/13/07 & 2.11 & 0.55 & 0.72 & No \\
\hline 83 & $04 / 24 / 07$ & $10 / 11 / 07$ & 1.84 & 0.42 & 1.99 & No \\
\hline 84 & $05 / 22 / 07$ & $11 / 09 / 07$ & 2.10 & 0.51 & 3.36 & No \\
\hline 85 & 06/20/07 & $12 / 07 / 07$ & 1.26 & 0.41 & 4.31 & No \\
\hline 86 & 07/19/07 & $01 / 09 / 07$ & 0.41 & 0.72 & 5.56 & No \\
\hline 87 & 08/16/07 & $02 / 06 / 07$ & -0.05 & 1.05 & 4.29 & Yes \\
\hline 88 & 09/14/07 & 03/06/07 & 0.09 & 1.08 & 2.82 & Yes \\
\hline \multicolumn{3}{|c|}{ Average Excess Return } & 0.61 & 0.74 & 3.15 & \\
\hline \multicolumn{3}{|c|}{ Variance of the Return } & 1.03 & 1.53 & 8.52 & \\
\hline
\end{tabular}

Table 9. Excess Returns from Pairs Trading and Seasonality (Cont'd)

"Winter trade" is defined to be trades including the days from December to February. The winter trades in this table comprise four periods: from \#50 to \#54, from \#62 to \#66, from \#75 to \#79, and from \#87 to \#88. 


\begin{tabular}{lrrr}
\hline & AR(1) Coefficient $(\hat{\rho})$ & Standard Deviation $(\hat{\sigma})$ & Average Excess Return \\
\hline WTI Futures Spread & 0.994 & 0.062 & 0.61 \\
Heating Oil Futures Spread & 0.990 & 0.083 & 0.74 \\
Natural Gas Futures Spread & 0.981 & 0.257 & 3.15 \\
\hline
\end{tabular}

Table 10. Mean Reversion and Volatility

For all combinations of the spreads for each energy futures, the parameters of AR(1) coefficient $\rho$ and standard deviation $\sigma$ are estimated. From these estimates the average $\bar{\rho}$ and $\bar{\sigma}$ are computed. The average excess return is obtained from Figure 5.

\begin{tabular}{lrrcr}
\hline & mean & standard deviation & $r$ & Sharpe Ratio \\
\hline WTI & 0.61 & 1.01 & 0.04 & 0.56 \\
HO & 0.74 & 1.27 & 0.04 & 0.55 \\
NG & 3.15 & 2.92 & 0.04 & 1.07 \\
\hline
\end{tabular}

Table 11. Risk-adjusted Returns

We assume that a risk-free rate is $4 \%$ to calculate the Sharpe ratio.

\begin{tabular}{lrccccccc}
\hline Parameters & \multicolumn{1}{c}{$\phi_{0,1}$} & $\phi_{0,2}$ & $\phi_{1,1}$ & $\phi_{1,2}$ & $\sigma_{1}$ & $\sigma_{2}$ & $p_{11}$ & $p_{22}$ \\
\hline Estimates & -0.002 & -0.010 & 0.981 & 0.953 & 0.0003 & 0.040 & 0.945 & 0.792 \\
Standard errors & 0.001 & 1.000 & 0.007 & 0.676 & 0.0000 & 0.015 & 0.007 & 0.029 \\
Log likelihood & 3946 & & & & & & & \\
AIC & -7876 & & & & & & & \\
SIC & -7892 & & & & & & & \\
\hline
\end{tabular}

Table 12. Regime-Switching Model

We estimated regime-switching model parameters using 1- and 2-month maturity NG futures price spreads. 


\section{Working Paper Series in Economics}

recent issues

No. 27 Takashi Kanamura, Svetlozar T. Rachev, Frank J. Fabozzi: A profit model for spread trading with an application to energy futures, May 2011

No. 26 Michele Leonardo Bianchi, Svetlozar T. Rachev, Young Shin Kim, Frank J. Fabozzi: Tempered infinitely divisible distributions and processes, May 2011

No. 25 Sebastian Kube, Michel André Maréchal and Clemens Puppe: The currency of reciprocity - gift-exchange in the workplace, April 2011

No. 24 Clemens Puppe and Attila Tasnádi: Axiomatic districting, April 2011

No. 23 Dinko Dimitrov and Clemens Puppe: Non-bossy social classification, April 2011

No. 22 Kim Kaivanto and Eike B. Kroll: Negative recency, randomization device choice, and reduction of compound lotteries, April 2011

No. 21 Antje Schimke and Thomas Brenner: Long-run factors of firm growth - a study of German firms, April 2011

No. 20 Aaron B. Scholz: Spatial network configurations of cargo airlines, April 2011

No. 19 Arne Beck: Public bus transport in Germany - a proposal to improve the current awarding system, April 2011

No.18 Nina Menz and Ingrid Ott: On the role of general purpose technologies within the Marshall-Jacobs controversy: the case of nanotechnologies, April 2011

No. 17 Berno Buechel: A note on Condorcet consistency and the median voter, April 2011 